\title{
Optimizing the method for generation of integration-free induced pluripotent stem cells from human peripheral blood
}

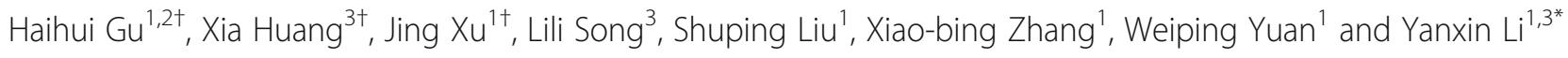

\begin{abstract}
Background: Generation of induced pluripotent stem cells (iPSCs) from human peripheral blood provides a convenient and low-invasive way to obtain patient-specific iPSCs. The episomal vector is one of the best approaches for reprogramming somatic cells to pluripotent status because of its simplicity and affordability. However, the efficiency of episomal vector reprogramming of adult peripheral blood cells is relatively low compared with cord blood and bone marrow cells.

Methods: In the present study, integration-free human iPSCs derived from peripheral blood were established via episomal technology. We optimized mononuclear cell isolation and cultivation, episomal vector promoters, and a combination of transcriptional factors to improve reprogramming efficiency.

Results: Here, we improved the generation efficiency of integration-free iPSCs from human peripheral blood mononuclear cells by optimizing the method of isolating mononuclear cells from peripheral blood, by modifying the integration of culture medium, and by adjusting the duration of culture time and the combination of different episomal vectors.
\end{abstract}

Conclusions: With this optimized protocol, a valuable asset for banking patient-specific iPSCs has been established.

Keywords: Induced pluripotent stem cell, Reprogramming, Integration free, Episomal vector

\section{Background}

Induced pluripotent stem cells (iPSCs) are a type of pluripotent stem cell resembling embryonic stem cells (ESCs) that can be directly generated from somatic cells by transcription factors [1]. The first common source for human iPSC derivation was skin dermal fibroblasts [2]. Since that discovery, a variety of somatic tissue cells have been reprogrammed to pluripotency [3-5]. Mononuclear cells (MNCs) from peripheral blood (PB) have been widely accepted as a more convenient and almost unlimited source of cells for reprogramming [6-10].

\footnotetext{
* Correspondence: liyanxin@scmc.com.cn

${ }^{+}$Haihui Gu, Xia Huang and Jing Xu contributed equally to this work. 'State Key Laboratory of Experimental Hematology, Institute of Hematology and Blood Diseases Hospital, Center for Stem Cell Medicine, Chinese Academy of Medical Sciences and Peking Union Medical College, Tianjin 200093, China

${ }^{3}$ Key Laboratory of Pediatric Hematology and Oncology, Ministry of Health, Pediatric Translational Medicine Institute, Shanghai Children's Medical Center, School of Medicine, Shanghai Jiao Tong University, Shanghai 200127, China Full list of author information is available at the end of the article
}

The original method using retroviral or lentiviral vectors expressing Oct4 (officially known as Pou5f1), Sox2, Klf4, and $\mathrm{c}-\mathrm{Myc}$ (known as Myc) has high reprogramming efficiency, but neither type of viral vector (retroviral and lentiviral) is ideal for clinical application. Viral vectors carry a risk for insertion mutation, which can result in tumorigenicity and genomic instability of iPSCs [11]. To make iPSC-based therapies safer, great efforts have been exerted to establish the cells without integration of an exogenous sequence into the cellular genomes. These techniques include using recombinant proteins or mRNA as an alternative to exogenous DNA [12, 13], Sendai virus methods [14], and episomal methods [15, 16]. Although episomal vectors are the most practical and efficient of these options, the reprogramming efficiency of this strategy needs to be improved $[17,18]$.

In this study, we optimized isolation of MNCs, modified the supplementation of culture medium, and adjusted the duration of culture time and the combination of different 
episomal vectors to improve the reprogramming technology of using human PB cells as donor cells. These optimizations have important implications for the clinical applications of iPSCs.

\section{Methods}

\section{Cell culture}

Primary murine embryonic fibroblasts (MEFs) were obtained from 13.5-day CD-1 IGS mouse embryos and cultured in standard DMEM containing 10\% FBS (Hyclone, Logan, UT, USA) and $2 \mathrm{mM}$ L-glutamine. The MEF cells (passage 3) were irradiated at 60 Gy and then plated on gelatinized plates. Irradiated MEFs $(2 \times$ $10^{5}$ cells) were coated onto six-well plates to support the culture for iPSC generation.

iPSCs were usually maintained in a feeder-free culture system. Briefly, we precoated the well plates with Matrigel (BD Biosciences), and then seeded the iPSCs and cultured them with E8 medium. When iPSCs reached 30-60\% confluence, they could be passaged routinely with EDTA $(0.5 \mathrm{M} / \mathrm{L})$.

Isolation and preparation of MNCs from peripheral blood All human whole blood samples were obtained from volunteers at the Institute of Hematology and Blood Diseases Hospital. Each PB sample was divided equally into four parts. MNCs were isolated from part 1 using standard Ficoll procedures by loading $35 \mathrm{ml}$ of diluted blood (blood:PBS $=1: 2$ ) onto a 15-ml layer of Ficoll-Paque PREMIUM ( $p=1.077 \mathrm{~g} / \mathrm{ml}$; Sigma Aldrich) in a $50-\mathrm{ml}$ conical tube. MNCs were isolated from part 2 using red cell lysis buffer procedures, with the addition of 4-fold of ACK buffer to the blood and centrifugation after $20 \mathrm{~min}$ of incubation in a $37{ }^{\circ} \mathrm{C}$ water bath. Hydroxyethyl starch (HES; Sigma Aldrich) of $60-\mathrm{kDa}$ molecular mass was added to PB from parts 3 and 4 in a 1:5 ratio. The supernatants collected after the sample remained stationary for $40 \mathrm{~min}$ at room temperature and were processed to yield MNCs either by the Ficoll method for part 3 or by the ACK method for part 4. In total, we used two isolating methods for enrichment of PB MNCs, including Ficoll and HES-Ficoll, and two isolating methods without enrichment, including ACK and HES-ACK. Except for MNCs, the other types of white blood cells would die quickly after being cultured in vitro, so we designated the isolated cells PB MNCs.

\section{Culture and expansion of MNCs from peripheral blood}

PB MNCs were expanded for 4-10 days in a serum-free medium supplemented with a mixture of cytokines. The two main culture media (erythroid culture medium (ECM) and granulocyte culture medium (GCM)) were tested. ECM included IMDM (50\%; Invitrogen) and Ham's F12 (50\%; Invitrogen) with ITS-X (100×; Invitrogen), chemically defined lipid concentrate (100×; Invitrogen), L-glutamine (100×; Invitrogen), ascorbic acid ( $0.05 \mathrm{mg} / \mathrm{ml}$; Sigma), BSA (5 mg/ml; Sigma), L-thioglycerol (200 $\mu \mathrm{M}$; Sigma), SCF (100 ng/ml; PeproTech), IL-3 (10 ng/ml; PeproTech), erythropoietin (2 U/ml; PeproTech), IGF-1 (40 ng/ml; PeproTech), dexamethasone (1 $\mu \mathrm{M}$; Sigma), and holotransferrin $(100 \mu \mathrm{g} / \mathrm{ml} ; \mathrm{R} \& \mathrm{D})$. GCM was supplemented with IMDM (50\%) and Ham's F12 (50\%), ITS-X (100×), chemically defined lipid concentrate (100x), L-glutamine $(100 \times)$, ascorbic acid $(0.05 \mathrm{mg} / \mathrm{ml})$, BSA $(5 \mathrm{mg} / \mathrm{ml})$, 1-thioglycerol $(200 \mu \mathrm{M})$, Thrombopoietin $(100 \mathrm{ng} / \mathrm{ml}$; PeproTech), SCF (100 ng/ml), Flt3 ligand (100 ng/ml; PeproTech), granulocyte-colony stimulating factor (G-CSF) (100 ng/ml; PeproTech), and IL-3 (10 ng/ml). During culture, we quantified the living cells by FACS staining and counted them automatically using a cell number counting machine (Bio-Rad).

\section{Nucleofection and generation of iPSCs}

Episomal vectors included three sets according to the different promoters: CAG, EF1, and SFFV. The CAG set included pEV CAG-OCT4-E2A-SOX2 (CAG-OS) and pEV CAG-MYC-E2A-KLF4 (CAG-MK); the EF1 set included pEV EF1-OCT4-E2A-SOX2 (EF1-OS) and pEV EF1-MYC-E2A-KLF4 (EF1-MK); and the SFFV set included pEV SFFV-OCT4-E2A-SOX2 (OS) and pEV SFFV-MYC-E2A-KLF4 (MK). To improve the reprogramming efficiency, we cloned pEV SFFV-BCL-XL (Bcl-XL), pEV SFFV-BCL2 (B), and pEV SFFV-Shp53 (Shp53). We added plasmids (4 $\mu$ g OS (CAG-OS or EF1-OS), $4 \mu \mathrm{g}$ MK (CAG-MK or EF1-MK) and $2 \mu \mathrm{g} B$ (Shp53 or BCL-XL)) to a sterile Eppendorf tube and mixed them with $100 \mu \mathrm{l}$ nucleofection buffer (Nucleofector ${ }^{\mathrm{Tm}}$ Kits for Human CD34 ${ }^{+}$Cells, Cat. No. VPA-1003; Lonza), and then transferred the mix to the cell pellet $\left(1 \times 10^{6}\right.$ cells). Using the kit-provided plastic pipette, we transferred the mixture of plasmids and cells into the provided cuvette to run the program (U008) on the nucleofection (2B; Lonza). After nucleofection, we directly transferred the mixture to the culture plate, which was already preseeded with feeder cells. The cells were cultured in reprogramming medium, which was composed of knockout DMEM/F12 medium (Invitrogen) and supplemented with 1\% L-glutamine (Invitrogen), $2 \mathrm{mM}$ nonessential amino acids (Invitrogen), 1\% penicillin/streptomycin (Cat. No. G255; Invitrogen), $50 \mathrm{ng} / \mathrm{ml}$ FGF2 (Invitrogen), 1\% ITS (BD Biosciences), and $50 \mu \mathrm{g} / \mathrm{ml}$ ascorbic acid (Sigma) for 7 days. The cells were then cultured in E8 medium (Invitrogen) until iPSCs were generated.

\section{Alkaline phosphate staining and immunocytochemistry}

Alkaline phosphatase (AP) staining was performed using a Fast Red substrate kit (Invitrogen). For detection of pluripotent stem cell marker antigens, cells were fixed 
with PBS containing 4\% paraformaldehyde for $10 \mathrm{~min}$ at room temperature. After being washed with PBS, the cells were incubated in PBS containing $0.1 \%$ Triton $\mathrm{X}-100$ for $20 \mathrm{~min}$ at room temperature. Fixed cells were stained with the primary antibodies SSEA-4 (1:100; Stemgent), TRA-1-60 (1/200; Stemgent), Oct-4 (1/200; Millipore), and Nanog (1/600; Santa Cruz). These primary antibodies were visualized with Alexa 488-conjugated goat anti-rabbit IgG, Alexa 594-conjugated goat anti-rabbit IgG, or Alexa Fluor 488-conjugated goat anti-mouse IgG (Invitrogen). Nuclei were stained with DAPI. Fluorescence images were acquired using a Zeiss inverted LSM confocal microscope (Carl Zeiss).

\section{Picking iPSC colonies}

When the colonies became visible to the naked eye, we started to pick them manually. We gently scratched the colonies using a 100- $\mu \mathrm{l}$ tip and transferred one colony to one well of the 24-well plates precoated with Matrigel and E8 medium. We typically picked $10-20$ colonies for each donor.

\section{Teratoma formation assay and histological analysis} Human iPSCs were suspended at $1 \times 10^{8}$ cells $/ \mathrm{ml}$ in PBS, and $100 \mu \mathrm{l}$ of the cell suspension $\left(1 \times 10^{7}\right.$ cells $)$ was injected subcutaneously into the dorsal flank of SCID mice (five mice per cell line). One month after the injection, tumors were surgically dissected from the mice. Teratomas were weighted, fixed in PBS containing 4\% formaldehyde, and embedded in paraffin. Sections were stained with hematoxylin and eosin.

\section{Gene expression analysis of iPSCs}

To assess their self-renewal propensities, we collected MNCs, iPSCs, and reprogrammed cells at 4, 5, and 7 days and extracted total RNA using the RNeasy plus kit (Qiagen). Real-time PCR was performed using the SYBR Green PCR Master Mix (Applied Biosystems, Foster City, CA, USA) on a 7500 Fast Real-Time PCR System (Applied Biosystems). The primer sets were as follows: Oct4-Hoct4 FP, 5'-ATTCAGCCAAACGACCATCT-3' and Hoct4 RP, 5'-GCTT CCTCCACCCACTTCT-3'; Sox2-HSox2 FP, 5'-CACAC TGCCCCTCTCACACA-3' and HSox2 RP, 5'-CCCTCC CATTTCCCTCGTTT-3'; and Nanog-HNanog FP, 5'-GC CGAAGAATAGCAATGGTGTG-3' and HNanog RP, $5^{\prime}$-G GAAGATAGAGGCTGGGGTAG-3'. To determine the average copy numbers of residual or integrated episomal vector in iPSC clones, real-time PCR analysis was performed. Total DNA (genomic and episomal) was extracted from iPSCs at passage 10. Two sets of primers were used to detect episomal vector DNA (in either episomal or integrated form): EBNA1-F, 5'-TTTAATACG ATTGAGGGCGTCT-3' and EBNA1-R, 5'-GGTTTTGAA GGATGCGATTAAG-3'; and OSW-F, 5'-GGATTACAA
GG ATGACGACGA-3' and OSW-R, 5'-AAGCCATAC GGGAAGCAATA-3'. The amplification program consisted of $50{ }^{\circ} \mathrm{C}$ for $2 \mathrm{~min}$ and $95^{\circ} \mathrm{C}$ for $10 \mathrm{~min}$, followed by $40 \mathrm{cy}-$ cles at $95{ }^{\circ} \mathrm{C}$ for $15 \mathrm{~s}$ and $60^{\circ} \mathrm{C}$ for $1 \mathrm{~min}$.

\section{Karyotyping and G-banding}

G-banding chromosome analysis of the iPSC line was performed following the protocol published by $\mathrm{Li}$ et al. [19]. Data were interpreted by a certified cytogenetic technologist.

\section{Propidium iodide staining of live/dead cells}

We used a flow cytometry assay to determine the ratio of live/dead cells. Briefly, harvested cells were washed with PBS, and then the cell pellet was suspended in PBS with $1 \mu \mathrm{g} / \mathrm{ml}$ propidium iodide and samples maintained in that solution at $4{ }^{\circ} \mathrm{C}$ protected from light before analysis on a flow cytometer.

\section{Statistical analysis}

Data are presented as mean \pm SEM. Two-tailed Student $t$ tests were performed, and $P<0.05$ was considered statistically significant.

\section{Results}

Isolating MNCs from human peripheral blood by different methods

PB MNCs are ideal for reprogramming iPSCs and have the potential to expedite advances in iPSC-based therapies [20]. To improve the generation efficiency of integration-free iPSCs from human PB MNCs, we optimized the method of generating them from human PB (Fig. 1a). In the first step, we used two isolating methods for enrichment of PB MNCs, Ficoll and HES-Ficoll, and two isolating methods without enrichment, ACK and HES-ACK. The total number of cells isolated from $1 \mathrm{ml}$ of $\mathrm{PB}$ with the four methods changed significantly. Yields with ACK and HES-ACK were significantly greater than with Ficoll or HES-Ficoll (Fig. 1b, Additional file 1: Figure S1A). In theory, the number of MNCs per milliliter of blood was almost the same in different groups from the same donor. Nonetheless, after 8 days of in-vitro culture, the number of live cells in the HES-Ficoll group was significantly greater than in the other groups (Fig. 1c, Additional file 1: Figure S1A). This result suggested that the HES-Ficoll group that yielded relatively purified MNCs initially was beneficial to cell culture.

We then generated the iPSCs from these cultured MNCs with a combination of reprogramming factors consisting of OCT4, SOX2, KLF4, and C-MYC. The ESC-like and TRA-1-60-positive colonies began to emerge at 7 days after nucleofection. Compared with the other three groups, the HES-Ficoll group generated significantly more TRA-1-60-positive colonies in every $1 \times 10^{6}$ live cells or every $1 \mathrm{ml}$ of PB than the other three groups (Fig. 1d, e). 


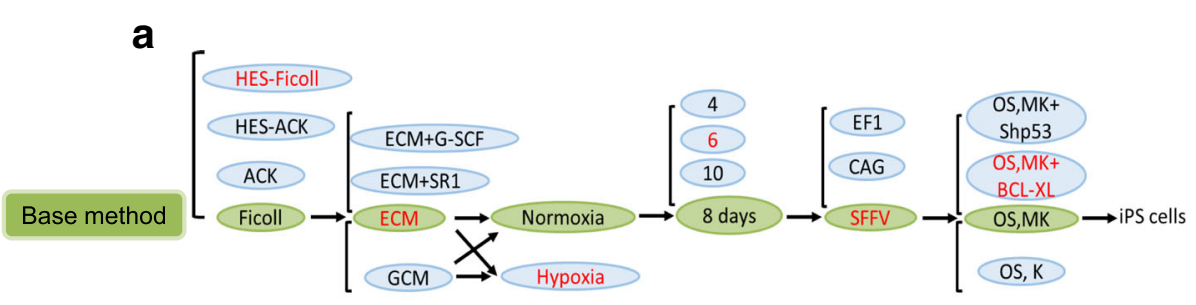

b

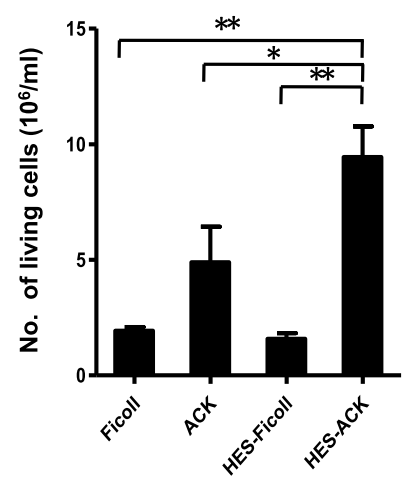

C
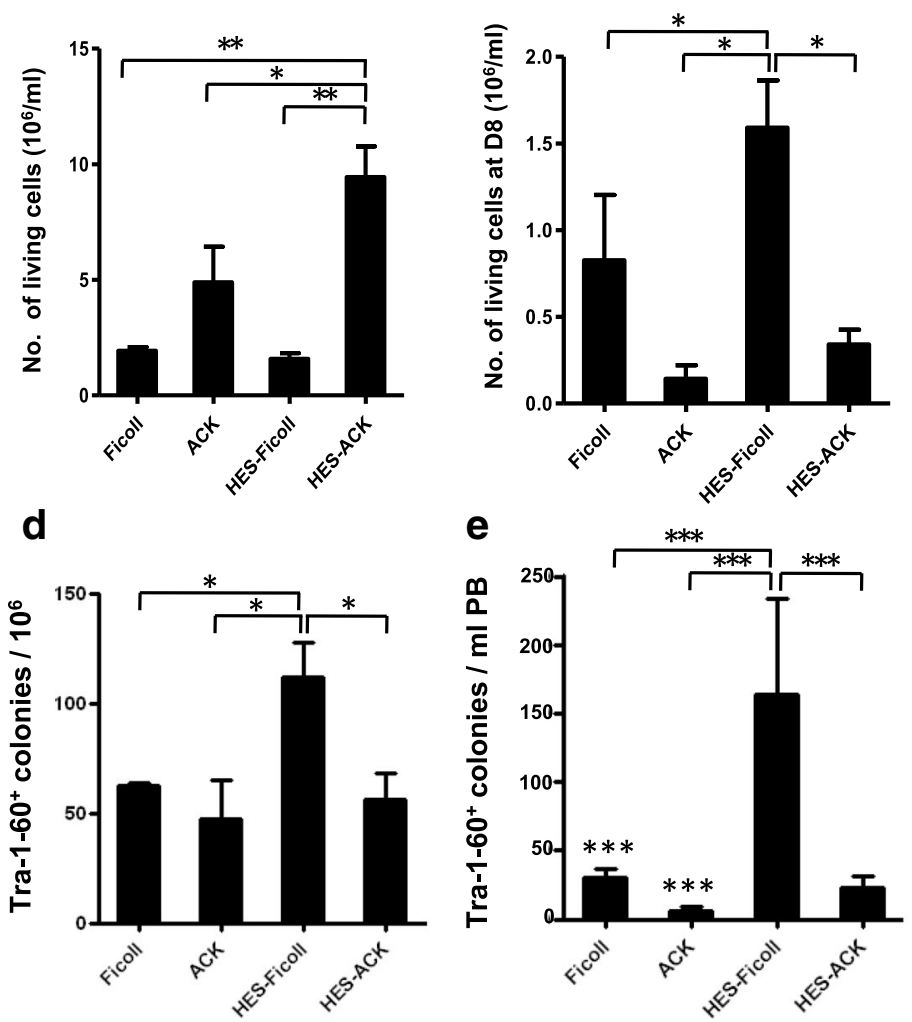

Fig. 1 Different effects of four MNC isolation methods on reprogramming of PB MNCs with episomal vectors. a Flow chart of optimized method for generation of integration-free iPSCs from human PB. Green ellipses highlight basic method. For figuring out best conditions, one factor was optimized while controlling others following indicated basic method. For each condition identified, at least three donors randomly selected and repeated three times per donor. $\mathbf{b}$ Number of living MNCs isolated from $1 \mathrm{ml}$ of PB by four methods at day 0 . $\mathbf{c}$ Number of living MNCs isolated from $1 \mathrm{ml}$ of PB after 8 days in culture. $\mathbf{d}$ Number of TRA-1-60-positive colonies generated from $1 \times 10^{6}$ PB MNCs. e Number of TRA-1-60-positive colonies generated from $1 \mathrm{ml}$ of PB by different isolating methods. PB MNCs cultured for 8 days before nucleofection. PB MNCs $\left(1 \times 10^{6}\right.$ cells $)$ nucleofected and then seeded into each well. TRA-1-60 staining of iPSCs at 3 weeks after nucleofection of PB MNCs with episomal vectors. Data presented as mean \pm SEM $(n=3) .{ }^{*} P<0.05 ;{ }^{*} P<0.01 ;{ }^{* * *} P<0.001$. OS, pEV SFFV-OCT4-E2A-SOX2; MK, pEV SFFV-MYC-E2A-KLF4; Shp53, pEV SFFV-Shp53;BCL-XL, pEV SFFV-BCL-XL; K, pEV SFFV- KLF4. HES hydroxyethyl starch, ECM erythroid culture medium, GCM granulocyte culture medium, G-CSF granulocyte-colony stimulating factor, SR1 StemRegenin1, iPS induced pluripotent stem, D day, PB peripheral blood

This finding reveals that the different MNC isolation methods can affect iPSC generation.

The effect of culture medium and culture time on the generation of integration-free iPSCs

$\mathrm{CD}_{4}{ }^{+}$cells in PB MNCs would be expended and differentiated after culture in vitro. Different culture conditions can affect the efficiency of generating integration-free iPSCs from human PB [21]. ECM was used to expand and culture the PB MNCs and improve their reprogramming efficiency (Fig. 2a). Compared with ECM medium alone, adding StemRegenin1 (SR1, the inhibitor of the aryl hydrocarbon receptor) or G-CSF to the ECM medium did not improve the reprogramming (Fig. 2b). This result indicated that the nucleated erythrocyte cells may be reprogrammable cells with high efficiency, except for CD34 ${ }^{+}$cells.

To confirm our hypothesis, we selected PB cells from patients with polycythemia vera (PRV) disease, which is an uncommon neoplasm in which the bone marrow makes 

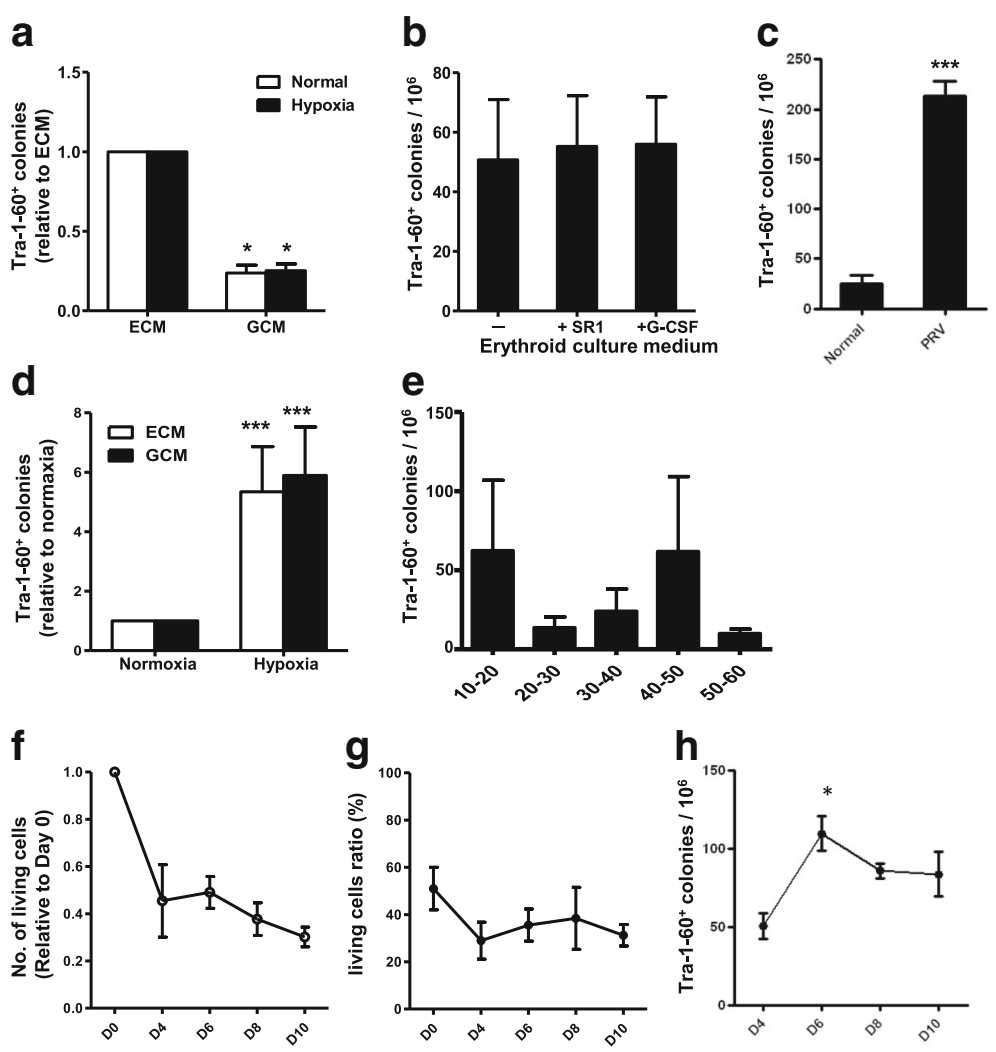

i

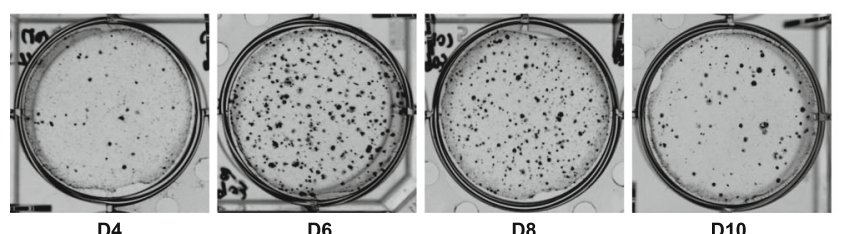

Fig. 2 Optimized culture conditions for generation of integration-free iPSCS. a ECM can improve reprogramming in both normoxic and hypoxic conditions. b Adding StemRegenin1 (SR1) or granulocyte-colony stimulating factor (G-CSF) to ECM does not affect reprogramming. PB MNCS cultured for 8 days before nucleofection with episomal vectors expressing OS, MK. PB MNCs $\left(1 \times 10^{6}\right.$ cells) nucleofected and then seeded into each well. Numbers of TRA-1-60-positive iPSC colonies counted 3 weeks after nucleofection. c Reprogramming efficiency of PB MNCs from four healthy volunteers and two polycythemia patients. d Hypoxia (3\%) increases reprogramming efficiency under both ECM and GCM conditions. e Reprogramming efficiency of all healthy volunteers at different ages. PB MNCs cultured for 8 days before nucleofection with episomal vectors expressing OS, MK. PB MNCS $\left(1 \times 10^{6}\right.$ cells) nucleofected and then seeded into each well. Numbers of TRA-1-60-positive iPSC colonies counted 3 weeks after nucleofection. $\mathbf{f}$ Number of living MNCs decreased after 10 days of culture with ECM. $\mathbf{g}$ Ratio of living MNCs changed after 10 days of culture with ECM. $\mathbf{h}$ Culturing PB MNCs for different numbers of days affected reprogramming efficiency. PB MNCs cultured for 4-10 days before nucleofection with episomal vectors expressing OS, MK. PB MNCs $\left(1 \times 10^{6}\right.$ cells) nucleofected and then seeded into each well. Numbers of TRA-1-60-positive iPSC colonies counted 3 weeks after nucleofection. i AP staining photographs after different days of culture with SFFV promoter episomal vectors. Data representative of three experiments (mean \pm SEM). ${ }^{*} P<0.05$; ${ }^{* *} P<0.001$. ECM erythroid culture medium, GCM

granulocyte culture medium, PRV polycythemia vera, D day

too many red blood cells. PRV involves elevated hemoglobin level and hematocrit, reflecting the increased number of circulating red blood cells. The results showed that the reprogramming efficiency of MNCs from a PRV patient's PB was significantly increased (Fig. 2c). After nucleofection, PB MNCs were cultured under normoxia or hypoxic conditions, respectively. Three weeks later, the number of TRA-1-60-positive colonies formed under hypoxic conditions (3\%) was four to six times higher than that in normoxic conditions (Fig. 2d).

To identify the effect of age on reprogramming, we selected healthy volunteers of different ages (10-20 years, five donors; 20-30 years, five donors; 30-40 years, four donors; 40-50 years, three donors; 50-60 years, three donors). The reprogramming efficiency was not affected by the age of the donors (Fig. 2e). 
In addition to change the culture conditions, separated PB MNCs were expanded in vitro for 8-10 days, as reported previously [17]. With the longer culture time, the total number of living cells gradually decreased (Fig. 2f, Additional file 1: Figure S1B), while the percentage of living cells remained unchanged (Fig. 2g, Additional file 1: Figure S1B). This result indicated that there was a certain rate of cells dead every day. To confirm the optimal culture time, we transfected the cells that were cultured respectively at days $4,6,8$, and 10 . At 3 weeks after nucleofection, the number of TRA-1-60-positive colonies was greatest at day 6 (Fig. 2h), and this result was confirmed by the AP staining method (Fig. 2i).

\section{The effect of vectors on the generation of iPSCs from peripheral blood}

We have noted that the reprogramming efficiency varied with different combinations of episomal vectors ( $\mathrm{pEB}$ $(\mathrm{C} 5+\mathrm{Tg})$, pEV $(\mathrm{OS}+\mathrm{MK}))$, which may be associated with different promoters of these vectors [22]. MNCs from human $\mathrm{PB}$ were transfected with the $\mathrm{pEV}$ episomal vectors
CAG, EF1, or SFFV, which had different promoters. At $48 \mathrm{~h}$, the expression of pluripotent genes (Fig. 3a) did not differ among the different promoters. Three weeks later, the number of TRA-1-60-positive colonies was assessed, and the SFFV promoter looked propitious for the reprogramming of the human PB cells (Fig. 3b). We then compared the combination of transcription vectors and found that the different combinations of episomal vectors and transcription factors had different effects on the formation of $\mathrm{PPSC}$ colonies. OSMK and BCL-XL represented the best or the more efficient combination [18, 22] (Fig. 3c, d).

\section{Characterization of iPSC colonies generated from the human peripheral blood cells}

We have established that iPSCs generated from PB MNCs using the optimized methods (Table 1) are indistinguishable in their behavior in culture and colony morphology from those of ESCs (Fig. 4a). Three iPSC lines were picked from the PB-iPSCs, and the expression of the pluripotency genes Oct4 and Sox2 in these three iPSCs were coincident with the H1 ESCs by real-time PCR (Fig. 4b). By immunostaining
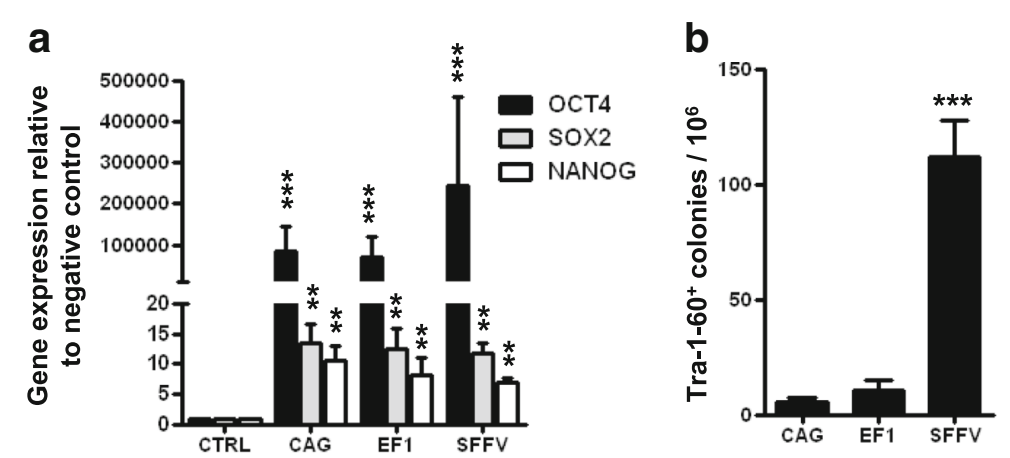

C

d
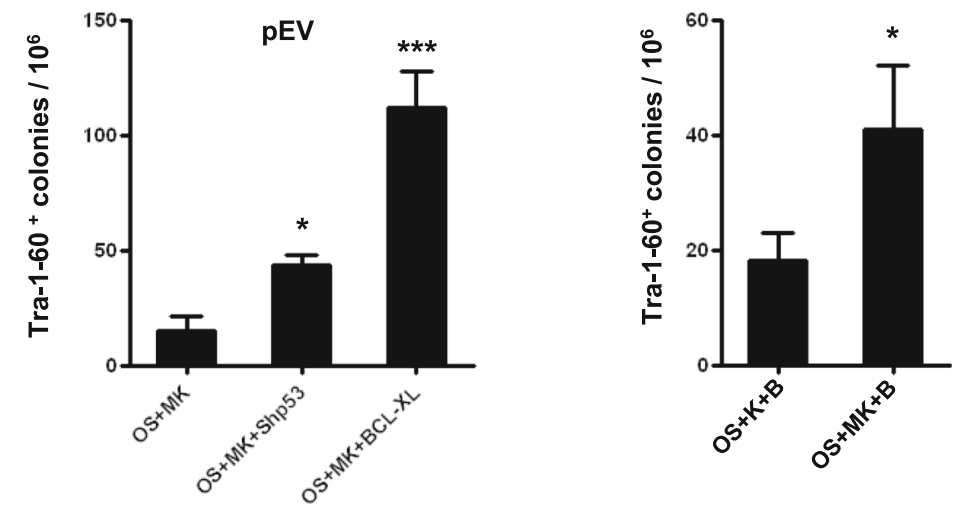

Fig. 3 Generation of integration-free iPSCs from PB MNCs with different episomal vectors. a Expression level of pluripotent genes $48 \mathrm{~h}$ after nucleofection by real-time PCR. CTRL group, PB MNCs before nucleofection. $\mathbf{b}$ Number of TRA-1-60-positive colonies generated from $1 \times 10^{6}$ PB MNCs 3 weeks after nucleofection. PB MNCs cultured for 8 days before nucleofection with episomal vectors (OS, MK) of different promoters (CAG, EF1, SFFV). PB MNCs $\left(1 \times 10^{6}\right.$ cells) nucleofected and then seeded into each well. c Number of TRA-1-60-positive colonies generated from $1 \times 10^{6}$ PB MNCs 3 weeks after nucleofection with different reprogramming factor-expressing episomal vectors. OS, pEV SFFV-OCT4-E2A-SOX2; MK, pEV SFFV-MYC-E2A-KLF4; BCl-XL, pEV SFFV-BCL-XL; Shp53, pEV SFFV-Shp53. d Effect of c-MYC on generation of integration-free iPSCs from human PB. B, pEV SFFV-BCL2; K, pEV SFFV-KLF4. Data presented as mean $\pm \operatorname{SEM}(n=6){ }^{*} P<0.05,{ }^{* *} P<0.01$, ${ }^{* *} P<0.001$ 
Table 1 Human iPSCs generated from PB with the optimized protocol

\begin{tabular}{|c|c|c|c|c|c|}
\hline Sample number & Genetic background & Age (years) & Male/female & Efficiency (\%) & Number of iPSC lines ${ }^{a}$ \\
\hline PB-1 & Normal & 39 & Female & 0.0004 & 4 \\
\hline PB-2 & Normal & 26 & Female & 0.001 & 5 \\
\hline PB-3 & Normal & 34 & Female & 0.002 & 8 \\
\hline PB-4 & Normal & 45 & Female & 0.002 & 13 \\
\hline PB-5 & Normal & 23 & Female & 0.0002 & 3 \\
\hline PB-6 & Normal & 20 & Male & 0.00053 & 12 \\
\hline PB-7 & Normal & 26 & Male & 0.0007 & 2 \\
\hline PB-8 & Normal & 47 & Male & 0.00253 & 1 \\
\hline PB-9 & Normal & 11 & Male & 0.0006 & 5 \\
\hline PB-10 & Normal & 59 & Male & 0.0009 & 3 \\
\hline PB-11 & Normal & 36 & Male & 0.00657 & 5 \\
\hline PB-12 & Normal & 10 & Male & 0.00387 & 8 \\
\hline PB-13 & Normal & 3 & Male & 0.001 & 3 \\
\hline PB-14 & Normal & 4 & Male & 0.0006 & 5 \\
\hline PB-15 & Normal & 28 & Female & 0.002 & 2 \\
\hline PB-16 & Normal & 24 & Female & 0.001 & 3 \\
\hline PB-17 & Normal & 26 & Female & 0.005 & 5 \\
\hline PB-18 & Normal & 24 & Male & 0.009 & 10 \\
\hline PB-19 & Normal & 23 & Female & 0.002 & 4 \\
\hline PB-20 & Normal & 20 & Male & 0.001 & 3 \\
\hline PB-21 & Normal & 24 & Female & 0.0008 & 7 \\
\hline PB-22 & PRV & 22 & Male & 0.00193 & 9 \\
\hline PB-23 & PRV & 22 & Male & 0.00243 & 9 \\
\hline PB-24 & JMML & 3 & Male & 0.0006 & 1 \\
\hline PB-25 & JMML & 3.9 & Male & 0.0008 & 2 \\
\hline PB-26 & JMML & 5 & Male & 0.00114 & 10 \\
\hline
\end{tabular}

iPSC induced pluripotent stem cell, JMML juvenile myelomonocytic leukemia, $P B$ peripheral blood, $P R V$ polycythemia vera

${ }^{a_{i} P S C}$ lines listed were identified by ESC characterization. We did not include iPSC lines without identification in the analysis

assay, we found that clones of iPSCs established from human $\mathrm{PB}$ retained typical characteristics of pluripotent stem cells such as the expression of embryonic stem cell markers (e.g., Oct4, NANOG, TRA-1-60, and SSEA4) (Fig. 4c). PB-iPSCs could form teratomas and differentiate into the three embryonic germ layers in immunodeficient mice (Fig. 4d). Cytogenetic analysis of all PB iPSC colonies showed a normal karyotype (Fig. 4e). All of these data demonstrated the pluripotency of these iPSCs. Ultimately, according to previous reports [23, 24], we passaged the iPSCs beyond 10 passages, and PCR-based detection of the vector sequence (EBNA1 and OSW) was not found in the expanded iPSCs after 10 passages (Fig. 4f). When we established iPSC lines, we also observed a certain proportion of clones undergoing differentiation (Additional file 2: Figure S2) and death in the same well derived from the same PB sample, which may indicate that there are differences between the different clones obtained from the same
PB sample using the same method of reprogramming and cultivation.

\section{Discussion}

In the present study, we optimized the episomal method to generate integration-free iPSCs from $\mathrm{PB}$ MNCs to iPSCs. First, we found that much purer MNCs can be obtained from $1 \mathrm{ml}$ of PB using the HES-Ficoll method compared to the other three options. After 6 days of in vitro culture, the most iPSC clones were acquired after transfection. ACK lysis buffer was used for lysis of the red blood cells. During this process, the polymorphonuclear cells were left in the ACK and HES-ACK procedures, which are not useful for MNC culture. On the other hand, Ficoll could not completely separate MNCs from red blood cells, while with the combination of HES and Ficoll most of the red blood cells could be 


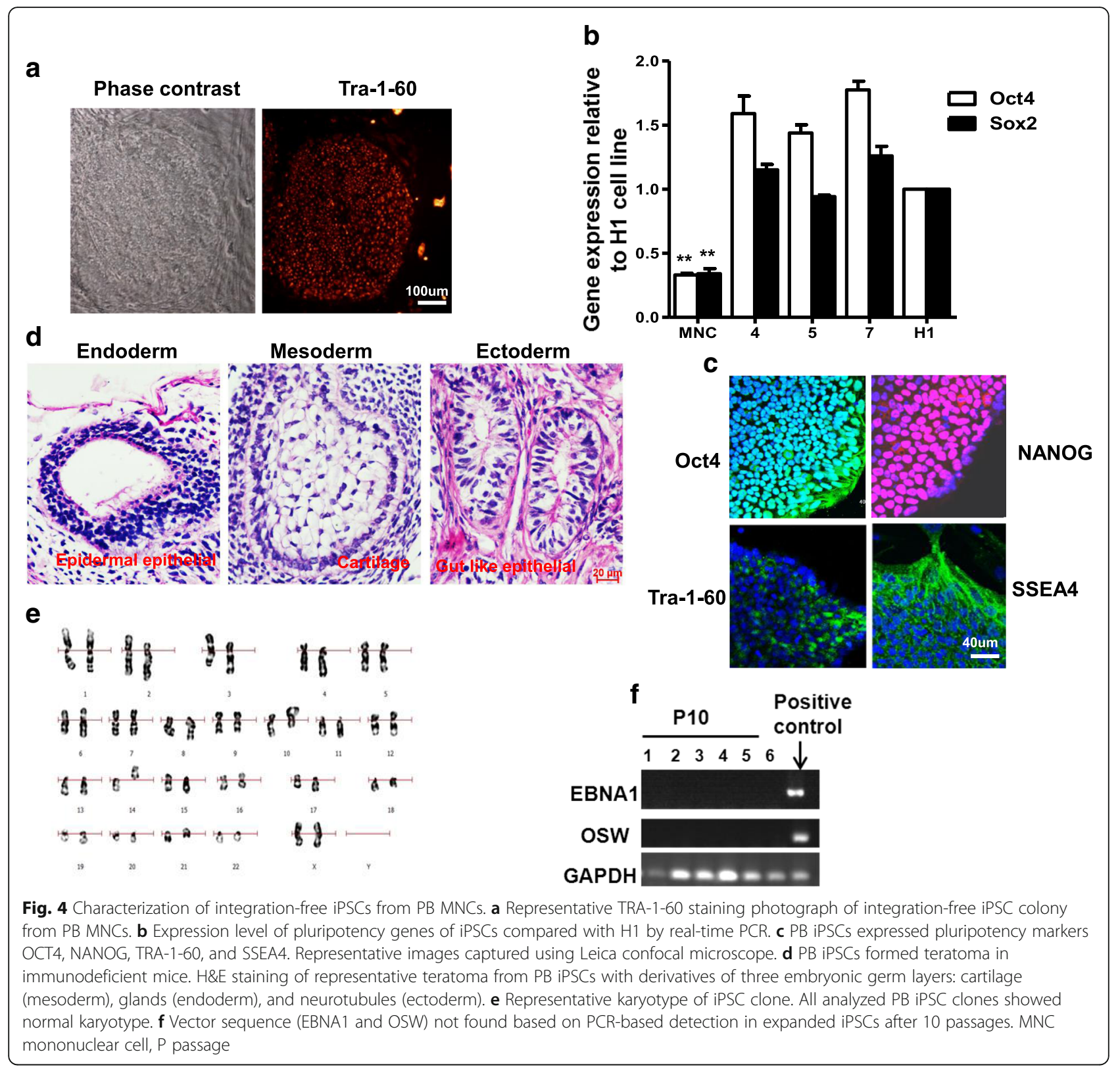

precipitated and removed. MNCs could then be separated from the remaining cells with the least damage to themselves.

$\mathrm{CD}^{+} 4^{+}$cells respond well to the cytokine cocktail and are reprogrammable with high efficiency [6, 25-27]. In our study, we found that the erythroid culture medium improved reprogramming efficiencies, favoring the expansion of erythroblasts instead of lymphocytes [17]. Therefore, adding granulocyte growth factors such as SR1 or G-CSF to ECM did not change the efficiencies, indicating that erythroblasts are the most important donor cell source except for $\mathrm{CD}_{3} 4^{+}$cells and can be reprogrammed with high efficiency.
MNCs from PRV patient PB cells had a high induction efficiency in forming iPSCs (Fig. 2c). The possible reason for this is that the erythroblasts are in specific epigenetic states that are more easily reprogrammed [23]. The reported PBMC reprogramming experiment recommends that PB MNCs are expanded over the course of 8-14 days in the culture medium [17]. We generated iPSCs from PB MNCs that had been cultured for different time periods and confirmed that the optimal culture time is on day 6 , based on comparing the number of TRA-1-60-positive and AP-positive colonies formed.

The virus encapsulated with SFFV as a vector can transfect human hematopoietic cells more efficiently and 
be expressed for a long time [28]. In our data, the expression of transcriptional genes did not increase significantly in the SFFV group at $48 \mathrm{~h}$ after transfection compared to the other promoters. We suggest that the persistence of expression may be the key reason for the high efficiency of reprogramming. Our results show that when the promoter of the episomal vector is SFFV, the reprogramming efficiency is most optimal (Fig. 3b).

Thus far, many studies have proved that different combinations of transcription factors can be applied successfully to cell reprogramming $[20,26]$. BCL-XL is well known for acting as an antiapoptotic protein [29], which is beneficial [30]; in addition, OSMK with BCL-XL has the most positive effect on the formation of iPSC colonies [22] (Fig. 3c, d).

Earlier studies have reported that hypoxia can improve survival of neural spine cells [31] and hematopoietic stem cells [32] and can inhibit the differentiation of ESCs [33]. Our study also confirmed that hypoxic conditions can improve the reprogramming efficiency of PB MNCs after nucleofection.

\section{Conclusions}

In the present study, we sought to improve the episomal method for generating iPSCs from $\mathrm{PB}$ MNCs and to lay some foundation for individualized iPSCs for future clinical application. With this optimized protocol, we improved the generation efficiency of integration-free iPSCs from human peripheral blood mononuclear cells, and a valuable asset for banking patient-specific iPSCs has been established.

\section{Additional files}

Additional file 1: Figure S1. FACS staining of live/dead cells. A Representative images of FACS staining of live/dead cells of PB MNCs by four PB MNC isolation methods at day 0 or after 8 days. B Representative images of FACS staining of live/dead cells of PB MNCs at indicated time points. PB MNCs isolated with Ficoll method. (PPTX 99 kb)

Additional file 2: Figure S2. Differentiated PB iPSC clones did not express pluripotency markers OCT4, NANOG, TRA-1-60, and SSEA4. Representative images captured using Leica confocal microscope. (PPTX 292 kb)

\section{Funding}

This work was supported in part by the National Natural Science Foundation of China (No. 81400152 to HG; No. 81470315 and No. 81772663 to YL). the Ministry of Science and Technology of China (No. 2012CB966601 to JX), the Shanghai Jiao Tong University Medical Engineering Cross Fund (No. YG2017MS32), and the Collaborative Innovation Center for Translational Medicine at Shanghai Jiao Tong University School of Medicine (fund TM201502).

\section{Availability of data and materials}

Please contact author for data requests.

\section{Authors' contributions}

HG carried out the cell culture studies and drafted the manuscript. XH carried out the immunoassays and performed the statistical analysis. JX participated in the cell culture and animal experiments. LS drafted the manuscript. SL carried out the cell culture studies. WY and XBZ participated in the design of the study. YL conceived of the study and participated in its design and coordination and helped to draft the manuscript. All authors read and approved the final manuscript.

\section{Ethics approval and consent to participate}

Written approval for human tissue collection and subsequent iPSC generation and genome/gene analyses performed in this study was obtained from the Ethics Committee for Human Genome/Gene Analysis Research at the Institute of Hematology and Blood Diseases Hospital, and written informed consent was obtained from each individual volunteer. All animal protocols were approved by the Institutional Animal Care and Use Committee, Institute of Hematology and Blood Diseases Hospital, CAMS/ PUMC. All surgery was performed under sodium pentobarbital anesthesia, and all efforts were made to minimize animal suffering.

\section{Competing interests}

The authors declare that they have no competing interests.

\section{Publisher's Note}

Springer Nature remains neutral with regard to jurisdictional claims in published maps and institutional affiliations.

\section{Author details}

${ }^{1}$ State Key Laboratory of Experimental Hematology, Institute of Hematology and Blood Diseases Hospital, Center for Stem Cell Medicine, Chinese Academy of Medical Sciences and Peking Union Medical College, Tianjin 200093, China. ${ }^{2}$ Department of Transfusion Medicine, Shanghai Changhai Hospital, Second Military Medical University, 168 Changhai Road, Shanghai 200433, China. ${ }^{3}$ Key Laboratory of Pediatric Hematology and Oncology, Ministry of Health, Pediatric Translational Medicine Institute, Shanghai Children's Medical Center, School of Medicine, Shanghai Jiao Tong University, Shanghai 200127, China.

Received: 17 January 2018 Revised: 17 April 2018

Accepted: 15 May 2018 Published online: 15 June 2018

\section{References}

1. Takahashi K, Yamanaka S. Induction of pluripotent stem cells from mouse embryonic and adult fibroblast cultures by defined factors. Cell. 2006;126: 663-76.

2. Takahashi K, Tanabe K, Ohnuki M, Narita M, Ichisaka T, Tomoda K, Yamanaka S. Induction of pluripotent stem cells from adult human fibroblasts by defined factors. Cell. 2007:131:861-72

3. Aasen T, Raya A, Barrero MJ, Garreta E, Consiglio A, Gonzalez F, Vassena R, Bilic J, Pekarik V, Tiscornia G, Edel M, Boue S, Izpisua Belmonte JC. Efficient and rapid generation of induced pluripotent stem cells from human keratinocytes. Nat Biotechnol. 2008:26:1276-84.

4. Streckfuss-Bomeke K, Wolf F, Azizian A, Stauske M, Tiburcy M, Wagner S, Hubscher D, Dressel R, Chen S, Jende J, Wulf G, Lorenz V, Schon MP, Maier LS, Zimmermann WH, Hasenfuss G, Guan K. Comparative study of human-induced pluripotent stem cells derived from bone marrow cells, hair keratinocytes, and skin fibroblasts. Eur Heart J. 2013:34:2618-29.

5. Sun N, Panetta NJ, Gupta DM, Wilson KD, Lee A, Jia F, Hu S, Cherry AM, Robbins RC, Longaker MT, Wu JC. Feeder-free derivation of induced pluripotent stem cells from adult human adipose stem cells. Proc Natl Acad Sci U S A. 2009:106:15720-5.

6. Loh YH, Agarwal S, Park IH, Urbach A, Huo H, Heffner GC, Kim K, Miller JD, $\mathrm{Nq} \mathrm{K}$, Daley GQ. Generation of induced pluripotent stem cells from human blood. Blood. 2009;113:5476-9.

7. Tancos Z, Varga E, Kovacs E, Dinnyes A, Kobolak J. Establishment of induced pluripotent stem cell (iPSC) line from a 75-year old patient with late onset Alzheimer's disease (LOAD). Stem Cell Res. 2016;17:81-3.

8. Tancos Z, Varga E, Kovacs E, Dinnyes A, Kobolak J. Establishment of induced pluripotent stem cell (iPSC) line from an 84-year old patient with late onset Alzheimer's disease (LOAD). Stem Cell Res. 2016;17:75-7.

9. Warren CR, O'Sullivan JF, Friesen M, Becker CE, Zhang X, Liu P, Wakabayashi Y, Morningstar JE, Shi X, Choi J, Xia F, Peters DT, Florido MHC, Tsankov AM, Duberow E, Cornisar L, Shay J, Jiang X, Meissner A, Musunuru K, Kathiresan S, Daheron L, Zhu J, Gerszten RE, Deo RC, Vasan RS, O'Donnell CI, Cowan CA. Induced pluripotent stem cell differentiation enables functional 
validation of GWAS variants in metabolic disease. Cell Stem Cell. 2017;20: 547-57. e547

10. Zhou H, Martinez H, Sun B, Li A, Zimmer M, Katsanis N, Davis EE, Kurtzberg J, Lipnick S, Noggle S, Rao M, Chang S. Rapid and efficient generation of transgene-free iPSC from a small volume of cryopreserved blood. Stem Cell Rev. 2015;11:652-65.

11. Okita K, Ichisaka T, Yamanaka S. Generation of germline-competent induced pluripotent stem cells. Nature. 2007:448:313-7.

12. Zhou H, Wu S, Joo JY, Zhu S, Han DW, Lin T, Trauger S, Bien G, Yao S, Zhu Y, Siuzdak G, Scholer HR, Duan L, Ding S. Generation of induced pluripotent stem cells using recombinant proteins. Cell Stem Cell. 2009;4:381-4.

13. Warren L, Manos PD, Ahfeldt T, Loh YH, Li H, Lau F, Ebina W, Mandal PK Smith ZD, Meissner A, Daley GQ, Brack AS, Collins JJ, Cowan C, Schlaeger TM, Rossi DJ. Highly efficient reprogramming to pluripotency and directed differentiation of human cells with synthetic modified mRNA. Cell Stem Cell. 2010;7:618-30.

14. Ban H, Nishishita N, Fusaki N, Tabata T, Saeki K, Shikamura M, Takada N, Inoue M, Haseqawa M, Kawamata S, Nishikawa S. Efficient generation of transgene-free human induced pluripotent stem cells (iPSCS) by temperature-sensitive Sendai virus vectors. Proc Natl Acad Sci U S A. 2011; 108:14234-9.

15. Schlaeger TM, Daheron L, Brickler TR, Entwisle S, Chan K, Cianci A, DeVine A, Ettenger A, Fitzgerald K, Godfrey M, Gupta D, McPherson J, Malwadkar P, Gupta M, Bell B, Doi A, Jung N, Li X, Lynes MS, Brookes E, Cherry AB, Demirbas D, Tsankov AM, Zon LI, Rubin LL, Feinberg AP, Meissner A, Cowan CA, Daley GQ. A comparison of non-integrating reprogramming methods. Nat Biotechnol. 2015;33:58-63.

16. Wen W, Zhang JP, Xu J, Su RJ, Neises A, Ji GZ, Yuan W, Cheng T, Zhang XB. Enhanced generation of integration-free iPSCs from human adult peripheral blood mononuclear cells with an optimal combination of episomal vectors. Stem Cell Reports. 2016;6:873-84.

17. Dowey SN, Huang X, Chou BK, Ye Z, Cheng L. Generation of integration-free human induced pluripotent stem cells from postnatal blood mononuclear cells by plasmid vector expression. Nat Protoc. 2012;7:2013-21.

18. Wen W, Zhang JP, Chen W, Arakaki C, Li X, Baylink D, Botimer GD, Xu J, Yuan W, Cheng T, Zhang XB. Generation of Integration-free Induced Pluripotent Stem Cells from Human Peripheral Blood Mononuclear Cells Using Episomal Vectors. J Vis Exp. 2017;119:e355091.

19. Li Y, Feng H, Gu H, Lewis DW, Yuan Y, Zhang L, Yu H, Zhang P, Cheng H, Miao W, Yuan W, Cheng SY, Gollin SM, Cheng T. The p53-PUMA axis suppresses iPSC generation. Nat Commun. 2013;4:2174.

20. Okita K, Yamakawa T, Matsumura Y, Sato Y, Amano N, Watanabe A, Goshima $\mathrm{N}$, Yamanaka S. An efficient nonviral method to generate integration-free human-induced pluripotent stem cells from cord blood and peripheral blood cells. Stem Cells. 2013;31:458-66.

21. Chou BK, Gu H, Gao Y, Dowey SN, Wang Y, Shi J, Li Y, Ye Z, Cheng T, Cheng L. A facile method to establish human induced pluripotent stem cells from adult blood cells under feeder-free and xeno-free culture conditions: a clinically compliant approach. Stem Cells Transl Med. 2015;4:320-32.

22. Su RJ, Baylink DJ, Neises A, Kiroyan JB, Meng X, Payne KJ, Tschudy-Seney B, Duan Y, Appleby N, Kearns-Jonker M, Gridley DS, Wang J, Lau KH, Zhang XB. Efficient generation of integration-free ips cells from human adult peripheral blood using BCL-XL together with Yamanaka factors. PLoS One. 2013;8:e64496

23. Chou BK, Mali P, Huang X, Ye Z, Dowey SN, Resar LM, Zou C, Zhang YA, Tong J, Cheng L. Efficient human iPS cell derivation by a non-integrating plasmid from blood cells with unique epigenetic and gene expression signatures. Cell Res. 2011;21:518-29.

24. Mack AA, Kroboth S, Rajesh D, Wang WB. Generation of induced pluripotent stem cells from CD34+ cells across blood drawn from multiple donors with non-integrating episomal vectors. PLoS One. 2011;6:e27956.

25. Liu T, Zou G, Gao Y, Zhao X, Wang H, Huang Q, Jiang L, Guo L, Cheng W. High efficiency of reprogramming CD34(+) cells derived from human amniotic fluid into induced pluripotent stem cells with Oct4. Stem Cells Dev. 2012;21:2322-32.

26. Meng X, Neises A, Su RJ, Payne KJ, Ritter L, Gridley DS, Wang J, Sheng M, Lau KH, Baylink DJ, Zhang XB. Efficient reprogramming of human cord blood CD34+ cells into induced pluripotent stem cells with OCT4 and SOX2 alone. Mol Ther. 2012;20:408-16.

27. Haase A, Gohring G, Martin U. Generation of non-transgenic iPS cells from human cord blood CD34(+) cells under animal component-free conditions. Stem Cell Res. 2017;21:71-3.
28. Yam PY, Li S, WU J, Hu J, Zaia JA, Yee JK. Design of HIV vectors for efficient gene delivery into human hematopoietic cells. Mol Ther. 2002;5:479-84.

29. Rhodes MM, Kopsombut P, Bondurant MC, Price JO, Koury MJ. BCl-x(L) prevents apoptosis of late-stage erythroblasts but does not mediate the antiapoptotic effect of erythropoietin. Blood. 2005;106:1857-63.

30. Kawamura T, Suzuki J, Wang YV, Menendez S, Morera LB, Raya A, Wahl GM, Izpisua Belmonte JC. Linking the p53 tumour suppressor pathway to somatic cell reprogramming. Nature. 2009;460:1140-4.

31. Morrison SJ, Csete M, Groves AK, Melega W, Wold B, Anderson DJ. Culture in reduced levels of oxygen promotes clonogenic sympathoadrenal differentiation by isolated neural crest stem cells. J Neurosci. 2000;20:7370-6.

32. Danet GH, Pan Y, Luongo JL, Bonnet DA, Simon MC. Expansion of human SCID-repopulating cells under hypoxic conditions. J Clin Invest. 2003;112:126-35.

33. Ezashi T, Das P, Roberts RM. Low $\mathrm{O} 2$ tensions and the prevention of differentiation of hES cells. Proc Natl Acad Sci U S A. 2005:102:4783-8.

\section{Ready to submit your research? Choose BMC and benefit from:}

- fast, convenient online submission

- thorough peer review by experienced researchers in your field

- rapid publication on acceptance

- support for research data, including large and complex data types

- gold Open Access which fosters wider collaboration and increased citations

- maximum visibility for your research: over $100 \mathrm{M}$ website views per year

At BMC, research is always in progress.

Learn more biomedcentral.com/submissions 